Article

\title{
Environmentally Friendly Gelatin/ $\beta$-Cyclodextrin Composite Fiber Adsorbents for the Efficient Removal of Dyes from Wastewater
}

\author{
Yu Chen ${ }^{1,2,3,+\oplus \text {, Yanli Ma }}{ }^{3,+}$, Weipeng Lu ${ }^{1,3, *}$, Yanchuan Guo ${ }^{1,2,3, *}$, Yi Zhu ${ }^{3}$, Haojun $\mathrm{Lu}^{3}$ and \\ Yeping Song ${ }^{3}$ \\ 1 Key Laboratory of Photochemical Conversion and Optoelectronic Material, Technical Institute of Physics \\ and Chemistry, Chinese Academy of Sciences, Beijing 100190, China; chenyubrc@mail.ipc.ac.cn \\ 2 University of Chinese Academy of Sciences, Beijing 100049, China \\ 3 Hangzhou Research Institute of Technical Institute of Physics and Chemistry, Chinese Academy of Sciences, \\ Hangzhou 310018, China; mayanli@mail.ipc.ac.cn (Y.M.); zhuyi@mail.ipc.ac.cn (Y.Z.); \\ luhaojun@mail.ipc.ac.cn (H.L.); songyeping@mail.ipc.ac.cn (Y.S.) \\ * Correspondence: luweipeng@mail.ipc.ac.cn (W.L.); yanchuanguo@mail.ipc.ac.cn (Y.G.); \\ Tel.: +86-571-8785-3765 (W.L.) \\ + These authors contributed equally to this work.
}

Received: 4 September 2018; Accepted: 20 September 2018; Published: 27 September 2018

\begin{abstract}
In this paper, environmentally friendly gelatin/ $\beta$-cyclodextrin $(\beta$-CD) composite fiber adsorbents prepared by electrospinning were used for the removal of dyes from wastewater. Fourier transform infrared spectroscopy (FTIR), scanning electron microscopy (SEM) and a universal materials tester were employed to characterize the internal structures, surface morphologies and mechanical strength of the composite fiber adsorbents. Additionally, the fiber was evaluated as an adsorbent for the removal of methylene blue (MB) from aqueous solution. The effects of the raw material ratio, $\mathrm{pH}$, temperature, concentration and adsorption time were studied. The results show that the gelatin $/ \beta-C D$ composite fiber adsorbents possess excellent mechanical strength and high adsorption efficiency for MB. The adsorption equilibrium and adsorption kinetics are well-described by the Langmuir isotherm model and the pseudo-second-order kinetic model, respectively. The theoretical maximum adsorption capacity is $47.4 \mathrm{mg} \cdot \mathrm{g}^{-1}$. Additionally, after nine successive desorption-adsorption cycles, the removal rate is still over $70 \%$. Moreover, the gelatin $/ \beta-C D$ composite fiber adsorbents exhibit excellent adsorption capability for basic fuchsin, gentian violet, brilliant blue $\mathrm{R}$ and malachite green dyes. Therefore, owing to the characteristics of degradability, low cost and high-efficiency, the gelatin $/ \beta-C D$ composite fiber can be used as an efficient adsorbent for the removal of dyes from wastewater.
\end{abstract}

Keywords: environmentally friendly; gelatin; $\beta-\mathrm{CD}$; adsorption; electrospinning

\section{Introduction}

Nowadays, with the advancement and technological improvement of the dyeing industry, dyes are widely used in cosmetics, leather, paper, printing, plastic and textile finishing. However, the water polluted by dyes poses a great threat to ecology and human health, because most of these dyes are not degradable, can resist aerobic digestion and are stable to heat, light and oxidizing agents. Therefore, the removal of dyes from wastewater is an urgent environmental problem. At present, various methods, such as adsorption, coagulation, electrochemistry, photocatalytic degradation and ultrafiltration, have been utilized to remove dyes from wastewater [1-6]. Among these processes, adsorption is one of the most attractive technologies due to its high efficiency, simplicity, low cost and simple technology [7]. Although many adsorbents, such as activated carbon [8], clay [9], silica [10] 
and other porous materials [11,12], have already been used in the removal of dyes from wastewater, nanofibrous absorbent materials prepared by electrospinning have attracted a great deal of attention in recent years. This is because the electrospinning technique is a facile and low-cost method to prepare nanofibers with high surface area and high porosity, small inter fibrous pore sizes, and high gas permeability [13-15]. Therefore, it has become a hot spot in the research of adsorbing materials for organic pollutants.

Recently, researchers have focused on modifying nanofibers by various functional groups $\left(-\mathrm{NH}_{2}\right.$, $\left.-\mathrm{COO}^{-}\right)$, cavity materials and porous silica materials to improve their dye adsorption ability [16-20]. Among them, $\beta$-cyclodextrin $(\beta-C D)$ has gained considerable attention in the modification of composite nanofibers for the adsorption of pollutants. The most outstanding feature of $\beta$-CD is its ability to form host-guest complexes with a wide range of organic waste molecules, due to a special hydrophobic internal cavity and a hydrophilic external surface [21-24]. In recent years, researchers have conducted many studies on $\beta$-CD-functionalized dye adsorbent materials. Kadam et al. used a composite polyacrylonitrile (PAN) / $\beta$-CD nanofiber membrane to capture air pollutants, including aerosols and volatile organic compounds (VOCs), which showed an excellent air filtration performance [25]. Schafer et al. prepared poly (ether sulfone) (PES) nanofibers with incorporated $\beta$-CD for micropollutant (MP) removal from water [26]. Zhao et al. demonstrated a feasible method in the preparation of a water-insoluble sericin / $\beta$-CD/poly (vinyl alcohol) composite nanofiber adsorbent by using electrospinning to remove the cationic dye methylene blue from aqueous solution [27]. Intensive research demonstrates that the composite $\beta$-CD nanofibers play an important role in the adsorption of dyes. However, it is noteworthy that polymers, such as polymethyl methacrylate, polystyrene, polyester and polyether sulfone, using in composite $\beta$-CD nanofibers, are non-degradable and thus can easily cause secondary pollution and have a low utilization ratio, which greatly restricts their applications for adsorption [28,29]. Therefore, it is of great value and urgency to search for composite nanofiber adsorption materials with a high degree of environmental friendliness and an excellent absorption performance.

As a peptide-based polymeric material, gelatin obtained from the partial hydrolysis of collagen is a very rich denatured biopolymer material in the animal field [30]. It has excellent ease of availability, broad resources of raw materials and low cost [31,32]. Moreover, as a kind of natural polymer, gelatin also has excellent degradability [33-35] in vivo and in vitro; thus, it is expected to replace traditional non-degradable materials in the fields of drug delivery, tissue engineering and food packaging [36,37]. In addition, gelatin is an amphoteric polymer that contains a large number of amino, carboxyl and hydroxyl groups, which can occur in gelatinization, and has a certain surface activity, such as electrostatic interactions and hydrogen bonds [38]. Therefore, due to the special structure and properties of gelatin, we assume that it can be used as an excellent adsorbent for the adsorption of dyes.

In this study, environmentally friendly gelatin / $\beta$-CD composite fiber adsorbents were synthesized by electrospinning with trifluoroethanol as a solvent, and glutaraldehyde was used as a cross-linking agent for the cross-linking of composite fibers (Scheme 1). The adsorption properties of the gelatin / $\beta$-CD composite fiber adsorbents were studied using methylene blue (MB) dye as an example. Moreover, as far as we know, this is the first time that gelatin-based composite fibers have been used for dyes adsorption. 


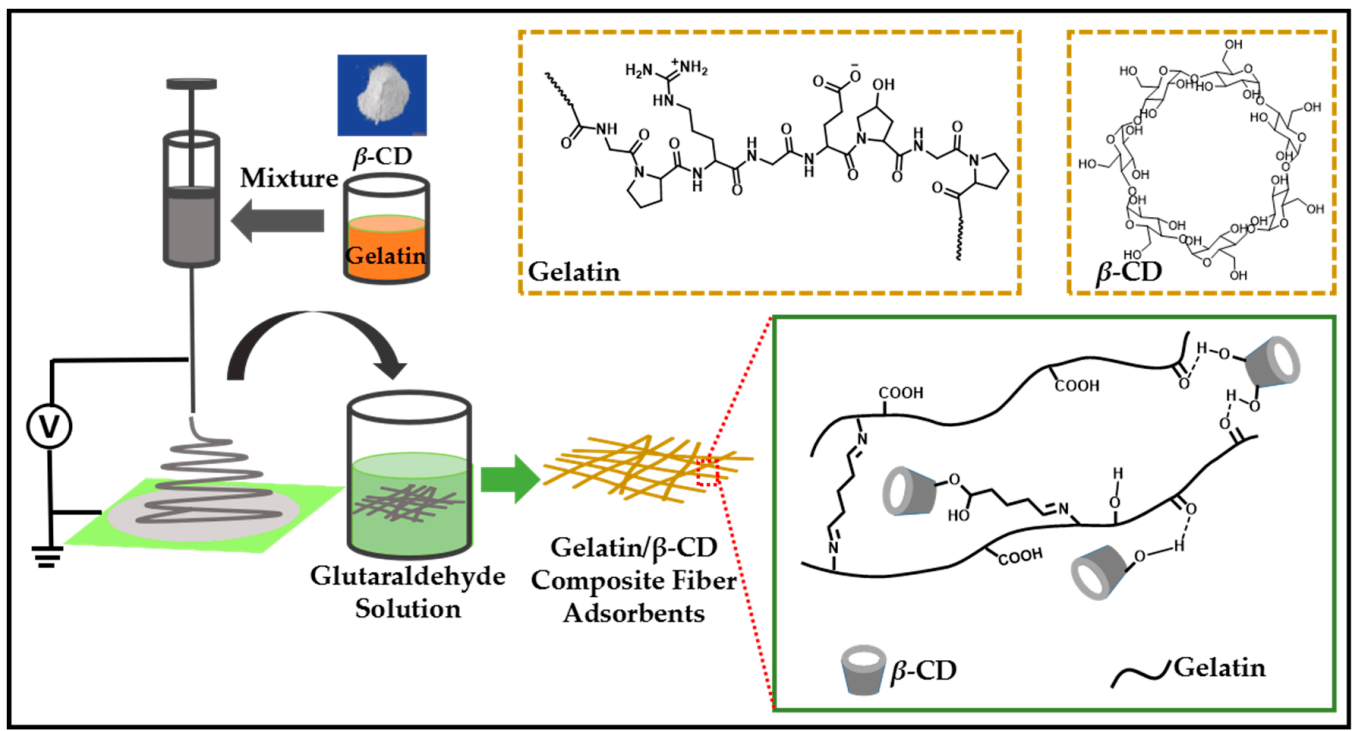

Scheme 1. The preparation process and structure of gelatin/ $\beta$-cyclodextrin $(\beta-C D)$ composite fiber adsorbents.

\section{Results and Discussion}

\subsection{Morphologies of the Gelatin/ $\beta-C D$ Composite Fiber Adsorbents}

In order to investigate the morphologies and structures of fiber adsorbents, field emission scanning electron microscope (FESEM) measurements were performed. As shown in Figure 1, S0', S1', S2', S3' and $\mathrm{S}^{\prime}{ }^{\prime}$ represent the composite fiber adsorbents without cross-linking, which contain $0,15,30,50$ and $65 \% \beta-\mathrm{CD}$, respectively. S0, $\mathrm{S} 1, \mathrm{~S} 2, \mathrm{~S} 3$ and $\mathrm{S} 4$ represent $\mathrm{SO}^{\prime}, \mathrm{S}^{\prime}, \mathrm{S}^{\prime}, \mathrm{S}^{\prime}$ and $\mathrm{S}^{\prime}$ cross-linked by glutaraldehyde, respectively. The average diameters of $\mathrm{SO}^{\prime}-\mathrm{S}^{\prime}{ }^{\prime}$ were about $3.3,3.5,3.7,3.9$ and 4.2 $\mu \mathrm{M}$, respectively. It can be seen that the pure gelatin fibers showed a uniform smooth surface, and the fiber thickness was consistent. However, because $\beta$-CD increased the viscosity of the electrospinning solution, the diameter of fibers appears to be thicker with the increase of the $\beta$-CD mass ratio in the composite fiber adsorbents. Furthermore, as the dyes' adsorbent, gelatin/ $\beta$-CD composite fibers need to have good physical/chemical stability in aqueous solution. Thus, glutaraldehyde was used as a cross-linking agent to improve the stability of the composite fiber adsorbents in a water atmosphere; the surface morphologies of S0-S4 are shown in Figure 1a-d. It demonstrates that the average diameter of the fiber increased after cross-linking, to about 3.7, 3.8, 4.0 and $4.3 \mu \mathrm{M}$, respectively. Moreover, the degrees of cross-linking and crimp between the fibers increased significantly and the cross-linking reaction caused the fibers to become denser and fuse at some intersections.
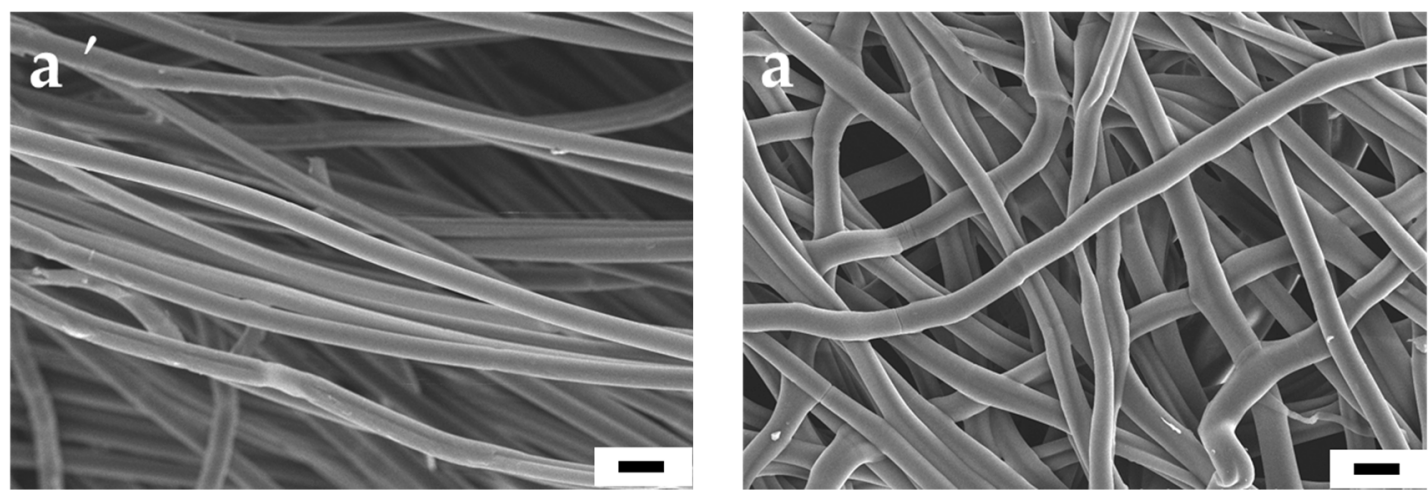

Figure 1. Cont. 

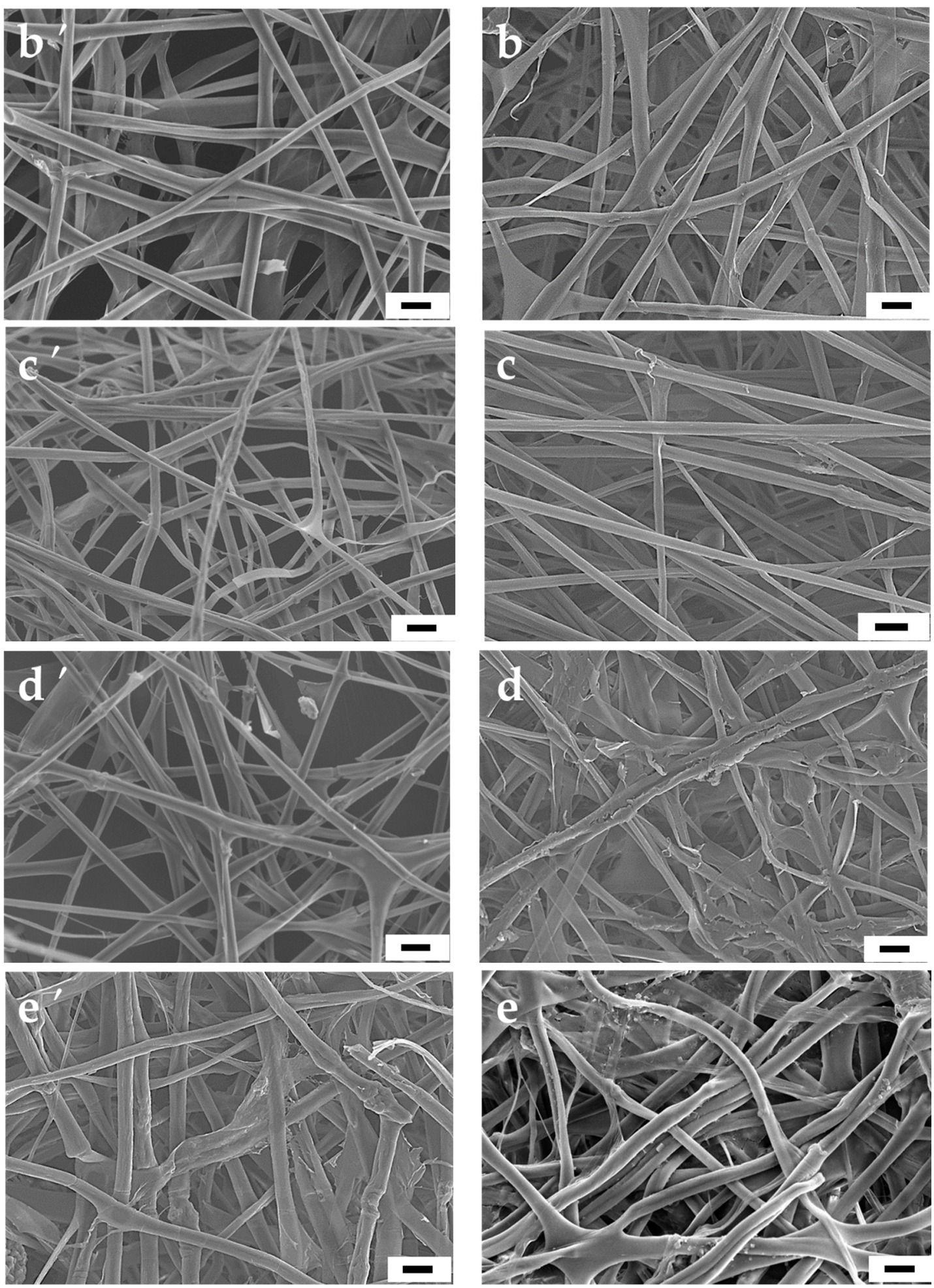

Figure 1. Field emission scanning electron microscope (FESEM) images of $\mathrm{S}^{\prime}\left(\mathbf{a}^{\prime}\right), \mathrm{S}^{\prime}\left(\mathbf{b}^{\prime}\right), \mathrm{S}^{\prime}\left(\mathbf{c}^{\prime}\right), \mathrm{S}^{\prime}$

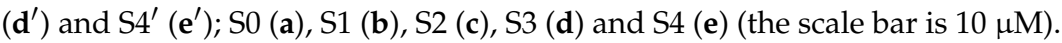

2.2. Fourier Transform Infrared Spectroscopy (FTIR) Characterization of Gelatin/ $\beta$-CD Composite Fiber Adsorbents

To ascertain the chemical structures of gelatin / $\beta$-CD composite fiber adsorbents, FTIR was carried out, the results of which are shown in Figure 2. Due to the stretching of $-\mathrm{OH}$ and $-\mathrm{NH}$, the gelatin molecule has a wide adsorption band at $3280 \mathrm{~cm}^{-1}$ [39]. Furthermore, the characteristic peaks at 
1629,1531 and $1237 \mathrm{~cm}^{-1}$ correspond to amide I, amide II and amide III, respectively, in which the amide I band is mainly attributed to the tensile vibration of $-\mathrm{C}=\mathrm{O}$, and the amide II and III bands were caused by the bending vibration of $-\mathrm{NH}$ and the stretching vibration of $-\mathrm{C}-\mathrm{N}$, respectively [40]. In addition, due to the reaction between the aldehyde group of glutaraldehyde and the amino lysine residue of gelatin, the stretching vibration peak of the imide group $(-\mathrm{CH}=\mathrm{N})$ appears at $1450 \mathrm{~cm}^{-1}[41]$. Simultaneously, attributed to the hydroxaldehyde condensation of $\beta-C D$ with glutaraldehyde, new peaks appear in the range of $1150-1050 \mathrm{~cm}^{-1}$, caused by the stretching vibration (alkyl-substituted ether) of $-\mathrm{C}-\mathrm{O}-\mathrm{C}-$ and $-\mathrm{C}-\mathrm{O}-$ [42]. Therefore, the above results confirm the successful cross-linking of gelatin with $\beta$-CD.

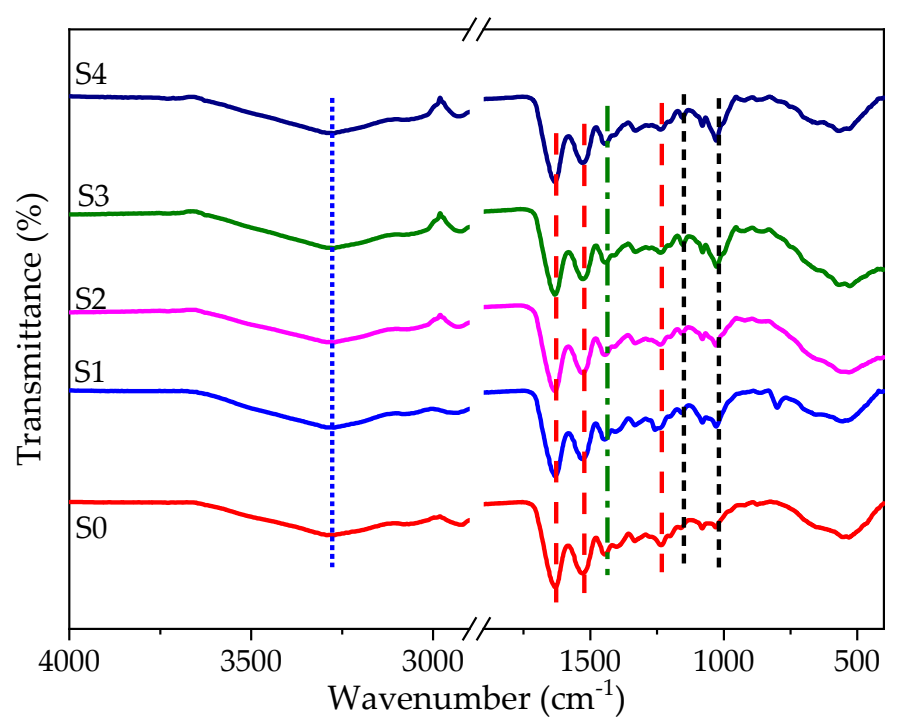

Figure 2. Fourier transform infrared spectroscopy (FTIR) spectrums of S0, S1, S2, S3 and S4.

\subsection{Mechanical Properties}

The mechanical properties of gelatin and gelatin $\beta-C D$ composite fiber adsorbents were evaluated using a universal materials tester; the stress-strain curves are shown in Figure 3. Compared to the pure gelatin fiber adsorbents (S0, 2.56 MPa), it is obvious that the tensile strength of the gelatin/ $\beta$-CD composite fiber adsorbents $(\mathrm{S} 1,2.76 \mathrm{MPa})$ increased after the introduction of $\beta$-CD. The enhanced mechanical properties followed from the dense linkage of the cross-linking network between the carboxylic groups or hydroxyl groups of gelatin and the hydroxyl groups of $\beta-\mathrm{CD}$, and hydrogen bonding between the gelatin matrix and the $-\mathrm{OH}$ group of $\beta$-CD. Furthermore, the cross-linking between gelatin and $\beta$-CD limited the movement of gelatin chains. However, as the content of $\beta$-CD increased, the tensile strength gradually decreased to $0.57 \mathrm{MPa}$. Although the uniform dispersion and good compatibility of gelatin and $\beta-C D$ can improve the tensile strength of composite fiber adsorbents, excessive $\beta$-CD will accumulate and separate from the gelatin matrix, resulting in a gradual decline in tensile strength. Simultaneously, the elongation of adsorbents decreased gradually. After researching the literature [43-47], we think that although the addition of cyclodextrin leads to a decrease in the elongation at break and tensile strength, the adsorbent still shows good mechanical properties. 


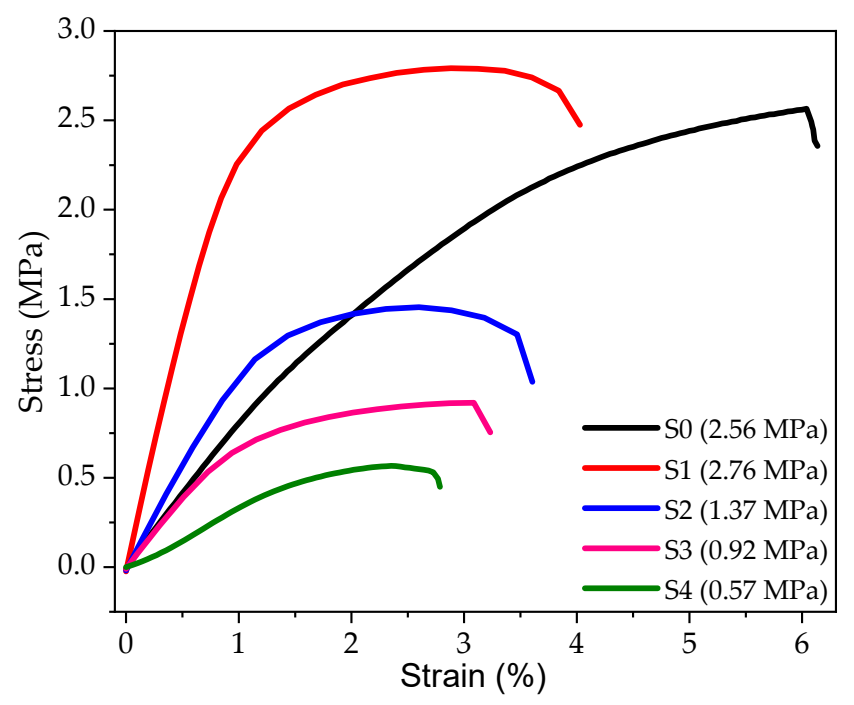

Figure 3. Tensile stress-strain curves of gelatin $/ \beta-C D$ and gelatin fiber adsorbents.

\subsection{MB-Adsorption Behaviors}

\subsubsection{Adsorption Kinetics of Gelatin/ $\beta$-CD and Gelatin Fiber Adsorbents}

To investigate the adsorption characteristics of gelatin $/ \beta-C D$ and gelatin fiber adsorbents for $\mathrm{MB}$, adsorbent $(10.0 \mathrm{mg})$ was immersed in $8.0 \mathrm{~mL} \mathrm{MB}$ solution $\left(20 \mathrm{mg} \cdot \mathrm{L}^{-1}, \mathrm{pH}=8.0\right)$, after which the absorbance-wavelength curve was measured at different adsorption times via a Ultraviolet-visible spectroscopy (UV-1800, SHIMADZU, Tokyo, Japan) implement. The concentration values at the maximum absorption wavelength were calculated by the Lambert-Beer law. Finally, the adsorption capacity values at different adsorption times were obtained by Equation (8). The adsorption capacity-adsorption time curves are shown in Figure 4. Attributed to many available adsorption sites, there was a rapid adsorption process in the first $40 \mathrm{~min}$. With the extension of adsorption time, the adsorption sites decreased and MB molecules had to pass through the surface of the fibers into the fiber network, which resulted in a slower adsorption rate. The adsorption capacity became gradually saturated and reached the adsorption equilibrium [48]. In addition, as shown in Figure 4, since $\beta$-CD can form host-guest complexes with MB molecules, the adsorption property of gelatin $/ \beta$-CD composite fiber adsorbents improved compared to the pure gelatin fiber adsorbent (S0). Due to the best adsorption performance of S2, all the subsequent experimental studies take S2 as the research object.

In order to evaluate the dynamic mechanism of the adsorption process of the gelatin $/ \beta-C D$ composite fiber adsorbents for MB, the pseudo-first-order and the pseudo-second-order kinetic models were used to fit the kinetic data, and the rate-determining step was judged by the fitting degree [49]. The pseudo-first-order and the pseudo-second-order dynamic equations are shown in Equations (1) and (2), respectively [50]:

$$
\begin{gathered}
\log \left(q_{e}-q_{t}\right)=\log q_{e}-k_{1} t \\
\frac{t}{q_{t}}=\frac{1}{k_{2} q_{e}^{2}}+\frac{t}{q e^{\prime}}
\end{gathered}
$$

where $q_{t}$ and $q_{e}\left(\mathrm{mg} \cdot \mathrm{g}^{-1}\right)$ are the adsorption capacity at time $t$ and equilibrium time, respectively, and $k_{1}\left(\mathrm{~min}^{-1}\right)$ and $k_{2}\left(\mathrm{~g} \cdot \mathrm{min}^{-1} \cdot \mathrm{mg}^{-1}\right)$ are the pseudo-first-order and the pseudo-second order model rate constants, respectively.

According to the pseudo-first-order and the pseudo-second-order kinetic equation, the curves of $\log \left(q_{e}-q_{t}\right)$ vs. $t$ and $t / q_{t}$ vs. $t$ were plotted and the fitting parameters of adsorption kinetic equations were obtained. Figure $5 \mathrm{a}, \mathrm{b}$ shows the fitting diagrams of the pseudo-first-order and the pseudo-second-order dynamic model, respectively, and the obtained parameters are shown in Table 1 . The fitting degree of the models was determined by the linear regression coefficient $\left(R^{2}\right)$. 
The relatively larger $\mathrm{R}^{2}$ value indicates that the model could successfully describe the adsorption kinetics of gelatin/ $\beta-C D$ composite fiber adsorbents for MB [51]. It can be seen from Figure 5 that the linear relationship of $t / q_{t}$ vs. $t$ was better during the whole adsorption period, and that the $\mathrm{R}^{2}$ of the pseudo-second-order model was larger. Additionally, the calculated $q_{e}$ value was more consistent with the experimental data, indicating that the adsorption process followed the pseudo-second-order dynamic model. The adsorption of MB may be carried out by a surface exchange reaction until the surface functional sites are fully occupied, after which the MB molecules diffuse into the fiber network for further interactions, such as electrostatic forces, hydrogen bonds, van der Waals forces and inclusions effects.

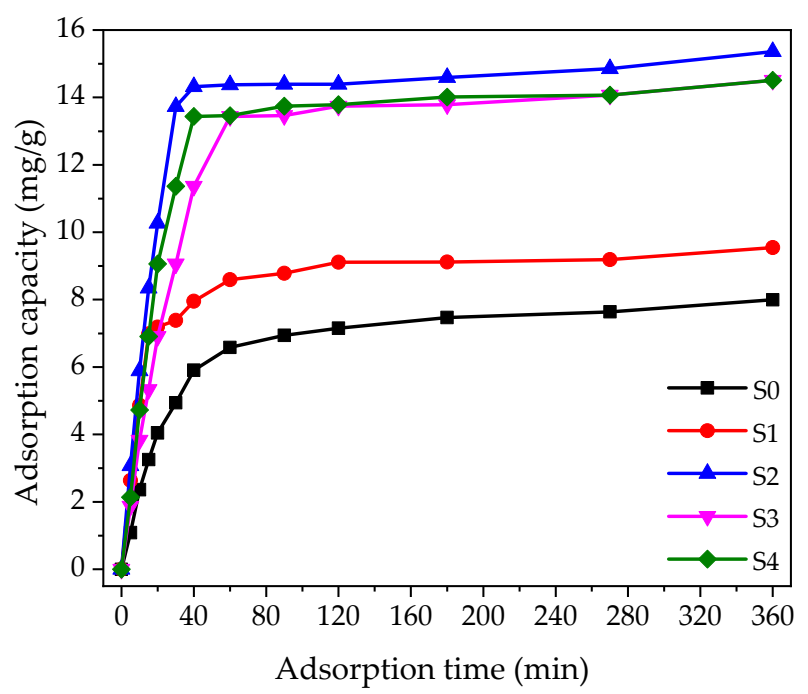

Figure 4. Kinetics of methylene blue (MB) adsorption onto gelatin and gelatin/ $\beta$-CD composite fiber adsorbents.

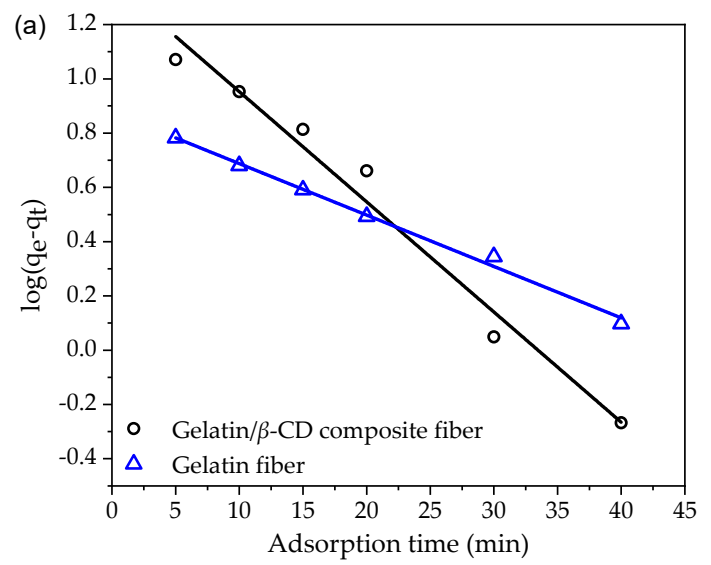

(a)

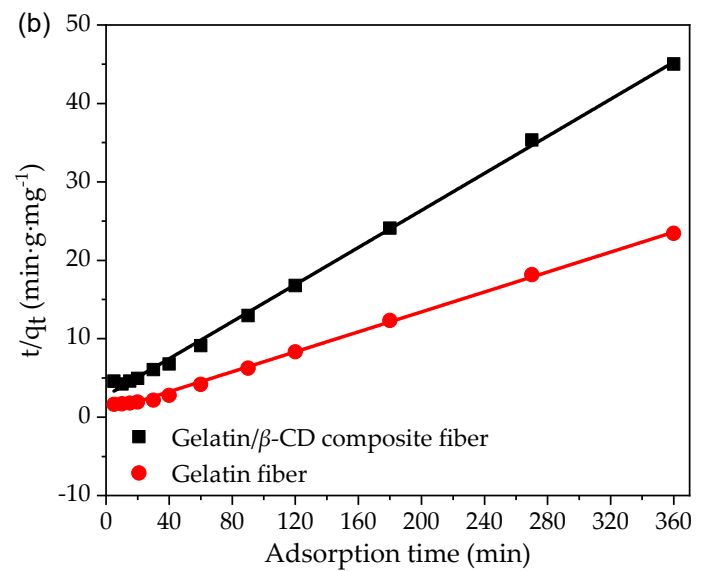

(b)

Figure 5. Adsorption kinetics of $\mathrm{MB}$ onto the gelatin and gelatin/ $\beta$-CD composite fiber adsorbents based on the pseudo-first-order (a) and pseudo-second-order (b) kinetic model.

Table 1. Kinetic parameters describing the adsorption of MB onto the gelatin and gelatin/ $\beta-\mathrm{CD}$ composite fiber adsorbents based on the pseudo-first-order and pseudo-second-order kinetic models.

\begin{tabular}{ccccccc}
\hline \multirow{2}{*}{$\begin{array}{c}\text { Adsorbent } \\
\text { Composition }\end{array}$} & \multicolumn{3}{c}{ Pseudo-First-Order } & \multicolumn{3}{c}{ Pseudo-Second-Order } \\
\cline { 2 - 7 } & $\boldsymbol{q}_{\boldsymbol{e}} / \mathbf{m g} \cdot \mathbf{g}^{-\mathbf{1}}$ & $\boldsymbol{k}_{\mathbf{1}} / \mathbf{m i n}^{-\mathbf{1}}$ & $\boldsymbol{R}^{\mathbf{2}}$ & $\boldsymbol{q}_{\boldsymbol{e}} / \mathbf{m g} \cdot \mathbf{g}^{-\mathbf{1}}$ & $\boldsymbol{k}_{\mathbf{1}} / \mathbf{m i n}^{\mathbf{- 1}}$ & $\boldsymbol{R}^{\mathbf{2}}$ \\
\hline Gelatin & 7.5 & 0.0406 & 0.9716 & 8.5 & 0.0198 & 0.9977 \\
Gelatin/ $\beta$-CD & 22.9 & 0.0189 & 0.9924 & 15.7 & 0.0015 & 0.9981 \\
\hline
\end{tabular}




\subsubsection{Adsorption Equilibrium}

The distribution of dye molecules between the adsorbent and the equilibrium solution could be expressed using various equations. The Langmuir and Freundlich isotherms are commonly used; these formulas are shown in Equations (3) and (5) [52].

The equation of Langmuir is represented as follows:

$$
\frac{c_{e}}{q_{e}}=\frac{1}{K_{L} * q_{m}}+\frac{c_{e}}{q_{m}}
$$

where $c_{e}\left(\mathrm{mg} \cdot \mathrm{L}^{-1}\right)$ is the equilibrium concentration of $\mathrm{MB}\left(\mathrm{mg} \cdot \mathrm{L}^{-1}\right)$ and $q_{e}\left(\mathrm{mg} \cdot \mathrm{g}^{-1}\right)$ is the equilibrium adsorption capacity of the MB adsorbed onto the gelatin $/ \beta-C D$ composite fiber adsorbents. $q_{m}$ is the maximum adsorption capacity of the adsorbent.

For the Langmuir adsorption process, the basic adsorption characteristics can be expressed in the separation factor $\left(R_{L}\right)$ which is defined by the following equation [53]:

$$
R_{L}=\frac{1}{1+c_{0} \times K_{L}}
$$

where $c_{0}$ is the initial concentration of $\mathrm{MB}\left(\mathrm{mg} \cdot \mathrm{L}^{-1}\right)$. The $R_{L}$ value indicates whether the adsorption process is irreversible $\left(R_{L}=0\right)$, favorable $\left(0<R_{L}<1\right)$, linear $\left(R_{L}=1\right)$ or unfavorable $\left(R_{L}>1\right)$ [54].

The Freundlich isotherm is represented as follows:

$$
\ln q_{e}=\ln K_{F}+\frac{1}{n F} \times \ln c_{e}
$$

According to the plot of $c_{e} / q_{e}$ vs. $c_{e}$, and $\ln q_{e}$ vs. $\ln c_{e}$, slop $1 / q_{m}$ and intercept $\left(\frac{1}{K_{L}} \times q_{m}\right)$ were obtained where $q_{m}$ represents the theoretical monolayer maximum adsorption capacity. The results are shown in Figure 6a,b. It can be seen that the Langmuir isotherm is linear over the entire concentration range and has a good linear correlation coefficient $\left(R^{2}=0.9106\right)$, indicating that the data is consistent with the Langmuir relationship. The value of $q_{m}$ is $47.4 \mathrm{mg} \cdot \mathrm{g}^{-1}$. Additionally, because the Langmuir equation assumes that the adsorbent surface is uniform, the Langmuir isotherm fitting results confirm the monolayer coverage of $\mathrm{MB}$ molecules and the uniform distribution of active sites onto the gelatin $/ \beta$-CD composite fiber adsorbents.

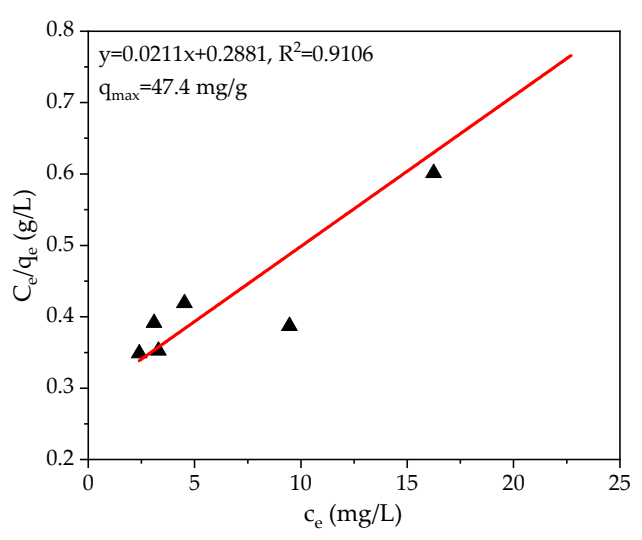

(a)

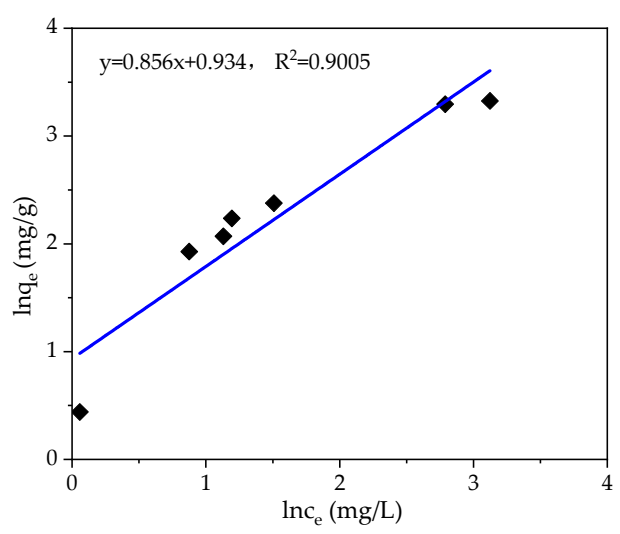

(b)

Figure 6. Adsorption isotherms of $\mathrm{MB}$ by gelatin/ $\beta$-CD composite fiber adsorbents: Langmuir isotherm (a) and Freundlich isotherm (b).

For the Langmuir adsorption process, the isotherm shape can be classified by the separation factor $\left(R_{L}\right)$ shown in Equation (4). The $R_{L}$ values of different initial dye concentrations are shown in 
Figure $7 \mathrm{~b}$. It can be observed that the value of $R_{L}$ is in the range of $0-1$, confirming the adsorption process is "favorable". Higher $R_{L}$ values at lower initial concentrations suggest that the adsorption is more favorable at lower MB concentrations.

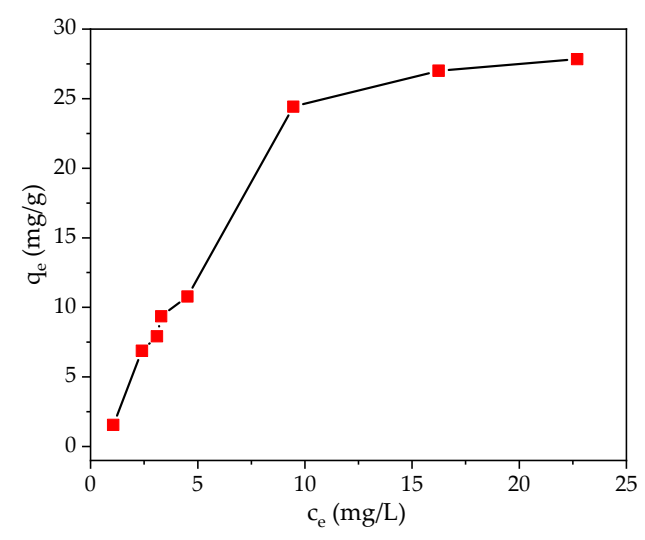

(a)

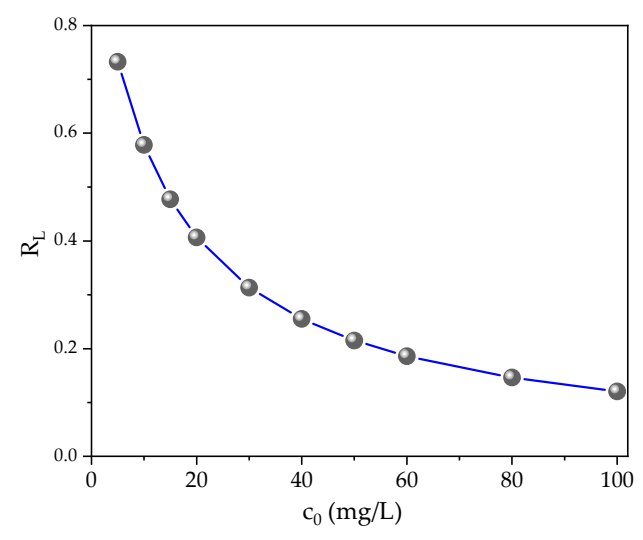

(b)

Figure 7. Adsorption isotherms of $\mathrm{MB}(\mathbf{a})$ and $\mathrm{R}_{\mathrm{L}}$ for the adsorption of $\mathrm{MB}(\mathbf{b})$ onto gelatin/ $\beta-\mathrm{CD}$ composite fiber adsorbents.

\subsubsection{Effects of $\mathrm{pH}$ and Temperature}

The $\mathrm{pH}$ of the MB solution affects the surface charge of the adsorbent and the structure of dye molecules. Therefore, it is an essential factor for studying the adsorption performance. In this paper, the effects of the $\mathrm{pH}$ of the $\mathrm{MB}$ solution on the adsorption performance of gelatin / $\beta$-CD composite fiber adsorbents (S2) and gelatin fiber adsorbents (S0) were analyzed; the results are shown in Figure 8a,c. As can be seen from the trend of the curves, the adsorption capacity and adsorption efficiency increased with the increase of $\mathrm{pH}$ in the range of 3.0-8.0. This phenomenon can be explained by the electrostatic action. At low $\mathrm{pH}$ values, the electrostatic repulsion between protonated adsorption sites on composite fibers and protonated dimethylamine groups from $\mathrm{MB}$ restrict the interaction between MB molecules and composite fiber adsorbents. Therefore, the adsorption process is inhibited. At the same time, positive $\mathrm{MB}$ molecules have difficulty forming an inclusion effect via the $\beta$-CD cavity. With the increase of $\mathrm{pH}$, positively charged $\mathrm{MB}$ molecules gradually change into a neutral state, and the carbonyl groups and hydroxyl groups with lone pairs on the gelatin/ $\beta$-CD composite fiber adsorbents surface can interact with $\mathrm{MB}$ molecules through electrostatic force, hydrogen bonds and van der Waals force. Moreover, the adsorption capacity of an MB molecule increases significantly after binding with a $\beta$-CD cavity. When the $\mathrm{pH}$ value of MB solution exceeds 8.0, some of the hydroxyl and carboxyl groups on the composite fibers become deprotonated, and the density of electron clouds for groups containing nitrogen $\mathrm{MB}$ increases, resulting in the increase of the repellent force [51]. On the other hand, what cannot be ignored is the influence of the isoelectric point of the fibers. According to the literature $[55,56]$, the isoelectric point (IEP) of the used gelatin (type B, basic-processed) is about 4.5-5.0. Therefore, when the $\mathrm{pH}$ of the $\mathrm{MB}$ solution is lower than the IEP, the gelatin surface presents as positively charged. Consequently, the positively charged gelatin rejects the protonated MB, which is not conducive to the adsorption of MB. When the $\mathrm{pH}$ of the MB solution increases, the gelatin surface changes into a neutral and negatively charged state and the electrostatic repulsion is reduced, resulting in an enhanced adsorption property. Compared to the adsorption capability of the gelatin fiber adsorbent (Figure 8c), the adsorption property of the gelatin / $\beta$-CD composite fiber adsorbent is enhanced due to the inclusion between the cavity of $\beta-\mathrm{CD}$ and MB. In conclusion, it can be inferred that the adsorption of gelatin / $\beta$-CD composite fiber adsorbents for MB is attributed to the forces of electrostatic force, hydrogen bonds, van der Waals force and inclusion effects. 


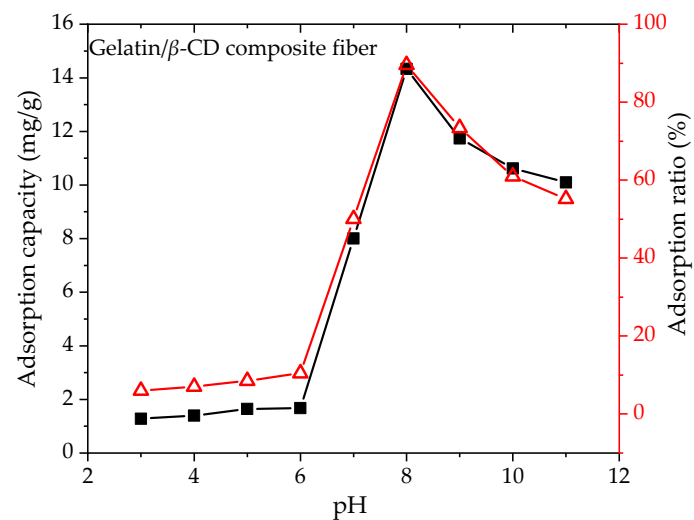

(a)

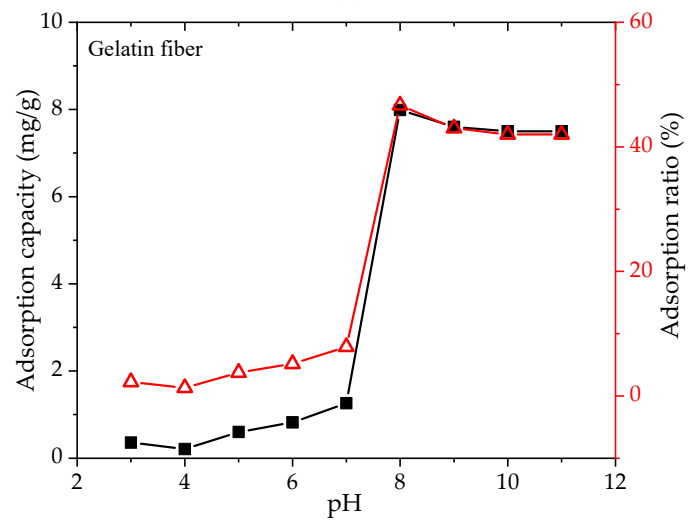

(c)

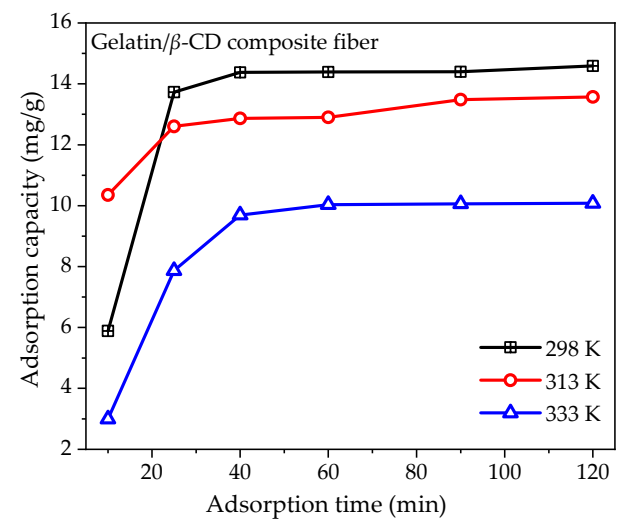

(b)

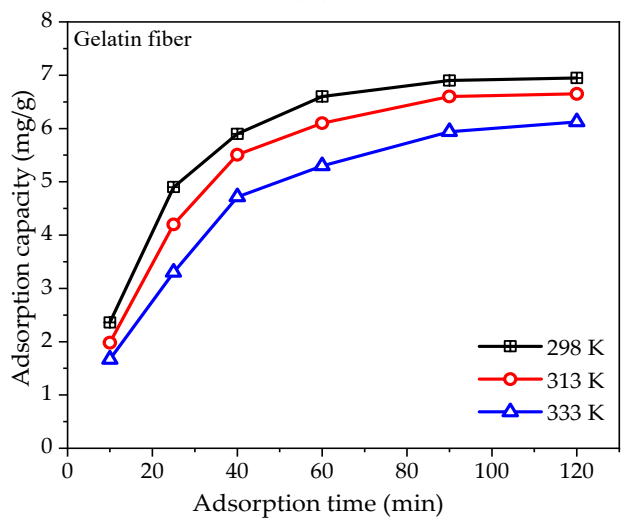

(d)

Figure 8. Effects of initial $\mathrm{pH}$ values $(\mathbf{a}, \mathbf{c})$ and temperature $(\mathbf{b}, \mathbf{d})$ on the adsorption property of MB.

Figure $8 \mathrm{~b}, \mathrm{~d}$ show $\mathrm{MB}$ adsorption onto gelatin/ $\beta$-CD composite fiber adsorbents and gelatin fiber adsorbents at different temperatures; the initial $\mathrm{pH}$ value is 8.0. The $\mathrm{MB}$ adsorption capacity $\left(14.6-10.1 \mathrm{mg} \cdot \mathrm{g}^{-1}\right)$ presents a significant decreasing trend with the rise in temperature $(298 \mathrm{k}-333 \mathrm{k})$. The reason may be that the processes of $\mathrm{MB}$ adsorption onto gelatin/ $\beta$-CD composite fiber adsorbents and gelatin fiber adsorbents are exothermic. Therefore, the increase of temperature is not beneficial to the positive movement of the adsorption process. The results suggest that $\mathrm{MB}$ adsorption on the adsorbent is favored at lower temperatures in the range of $20-60{ }^{\circ} \mathrm{C}$.

\subsubsection{Recyclability of Gelatin/ $\beta$-CD Composite Fiber Adsorbents}

The removal of $\mathrm{MB}$ from electrospun gelatin/ $\beta$-CD composite fiber adsorbents and the re-fixing of $\mathrm{MB}$ are the pivotal issues of adsorbent regeneration. Therefore, this paper evaluates the regeneration ability of gelatin/ $\beta$-CD composite fiber adsorbents by measuring the adsorption capacity of the desorbed gelatin $/ \beta-C D$ composite fiber adsorbents. The desorption-adsorption cycle's results are shown in Figure 9, and the first adsorption capacity of MB is regarded as " $100 \%$ ". It can be seen that the adsorption efficiency of gelatin / $\beta$-CD composite fiber adsorbents still reach $73 \pm 1.0 \%$ after nine desorption-adsorption cycles, meaning that the obtained electrospun gelatin/ $\beta$-CD composite fiber adsorbents possess good reusability. 


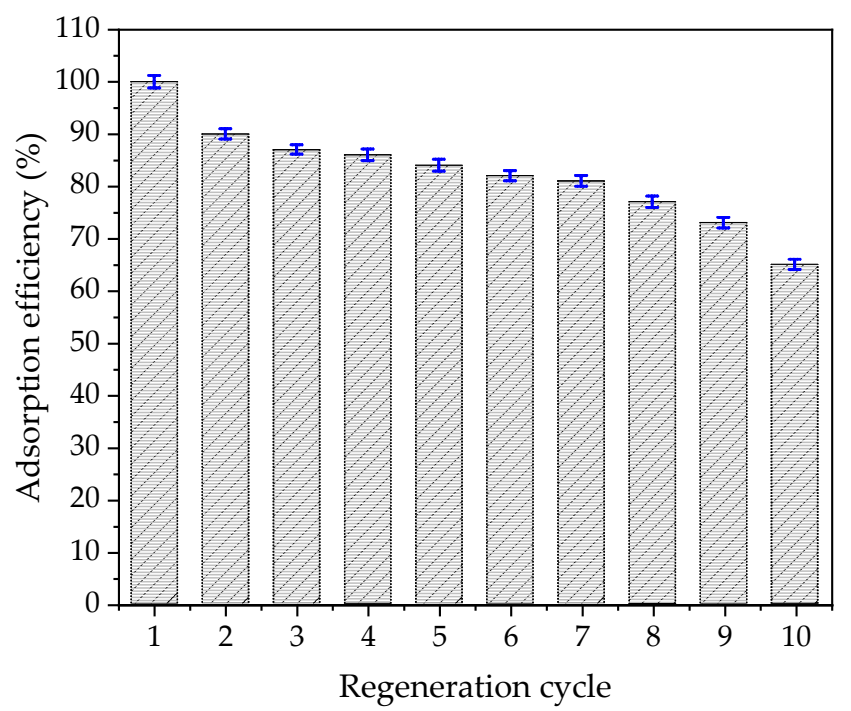

Figure 9. Desorption-adsorption cycles (adsorption efficiency of the first regeneration cycle was regarded as " $100 \% "$ ").

\subsubsection{Adsorption of Other Dyes}

In order to inspect the adsorption performance of gelatin/ $\beta$-CD composite fiber adsorbents with other dyes, the adsorption capacity and efficiency of basic fuchsin, gentian violet, brilliant blue $\mathrm{R}$ and malachite green were measured with the same adsorption conditions of $\mathrm{MB}$; the results are shown in Figure 10. It can be seen that gelatin $\beta$-CD composite fiber adsorbents possess high adsorption capacity $\left(12.0-16.0 \mathrm{mg} \cdot \mathrm{g}^{-1}\right)$ and adsorption efficiency $(>78 \%)$ for the four kinds of dyes. Based on the excellent adsorption properties for various dyes, gelatin $\beta-C D$ composite fiber adsorbents have great potential advantages as efficient adsorbents for the removal of dyes from wastewater.

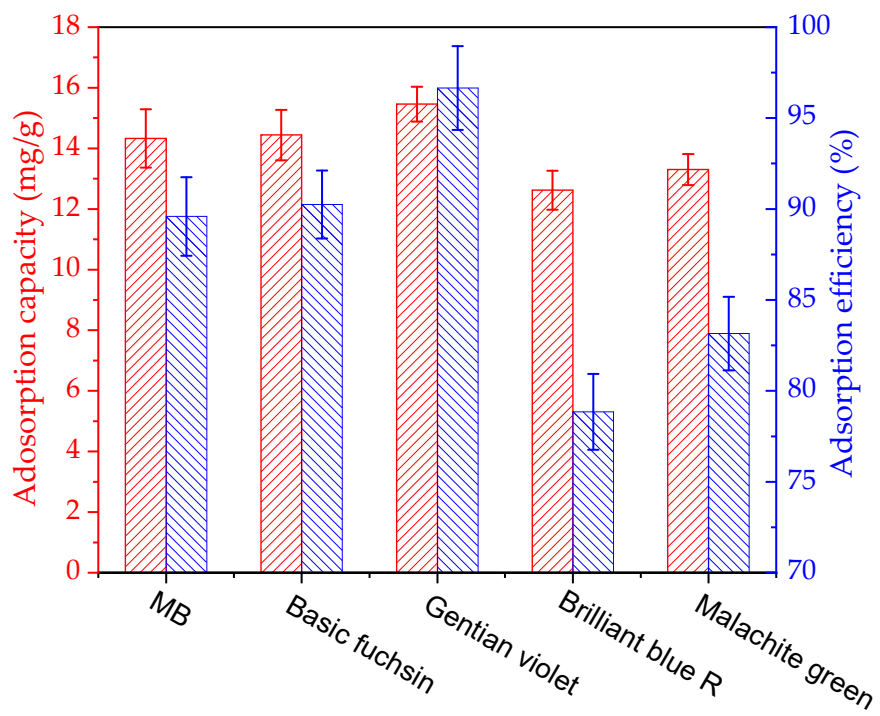

Figure 10. Adsorption capacity and efficiency of gelatin/ $\beta$-CD fiber adsorbents for different dyes.

\subsection{The Adsorption and Desorption Mechanism}

Based on the above results, the adsorption and desorption mechanism is shown in Scheme 2. The adsorption of $\mathrm{MB}$ onto the gelatin/ $\beta$-CD composite fiber adsorbents can be attributed to two processes: electrostatic interaction and complex host-guest interaction. Under electrostatic interaction, carboxyl groups in gelatin molecules can adsorb positively charged MB on the composite fiber 
adsorbents through positive and negative electrostatic interactions. For the host-guest interaction, we have mentioned that $\beta$-CD can be immobilized on gelatin molecules by cross-linking or hydrogen bonding; furthermore, $\beta$-CD can form host-guest complexes with MB molecules. Moreover, in order to further verify the successful adsorption of MB onto gelatin / $\beta$-CD fiber adsorbents, FTIR was used to characterize the changes of characteristic groups before and after the adsorption of MB. The results are shown in Figure 11. After adsorption, a new peak appeared at $1392 \mathrm{~cm}^{-1}$, which was attributed to the characteristic peak of $-\mathrm{C}=\mathrm{N}$ in the $\mathrm{MB}$ molecule [32]. In addition, compared to the fibers without $\mathrm{MB}$ adsorption, a red shift occurred at the characteristic peaks at 1524 and $1024 \mathrm{~cm}^{-1}$, which might have been caused by the hydrogen bond between $\mathrm{MB}$ and gelatin and the host-guest interaction between $\beta-C D$ and $\mathrm{MB}$, respectively. For the desorption process, the acid environment of desorbed solution could destroy the inclusion effect between $\mathrm{MB}$ and the cavity of $\beta-\mathrm{CD}$ and the interactions between $\mathrm{MB}$, gelatin and $\beta-C D$ such as electrostatic force, hydrogen bonds and van der Waals force. Consequently, MB molecules are separated from fiber adsorbent carriers easily. The result is consistent with the weak absorption of MB under acidic conditions.

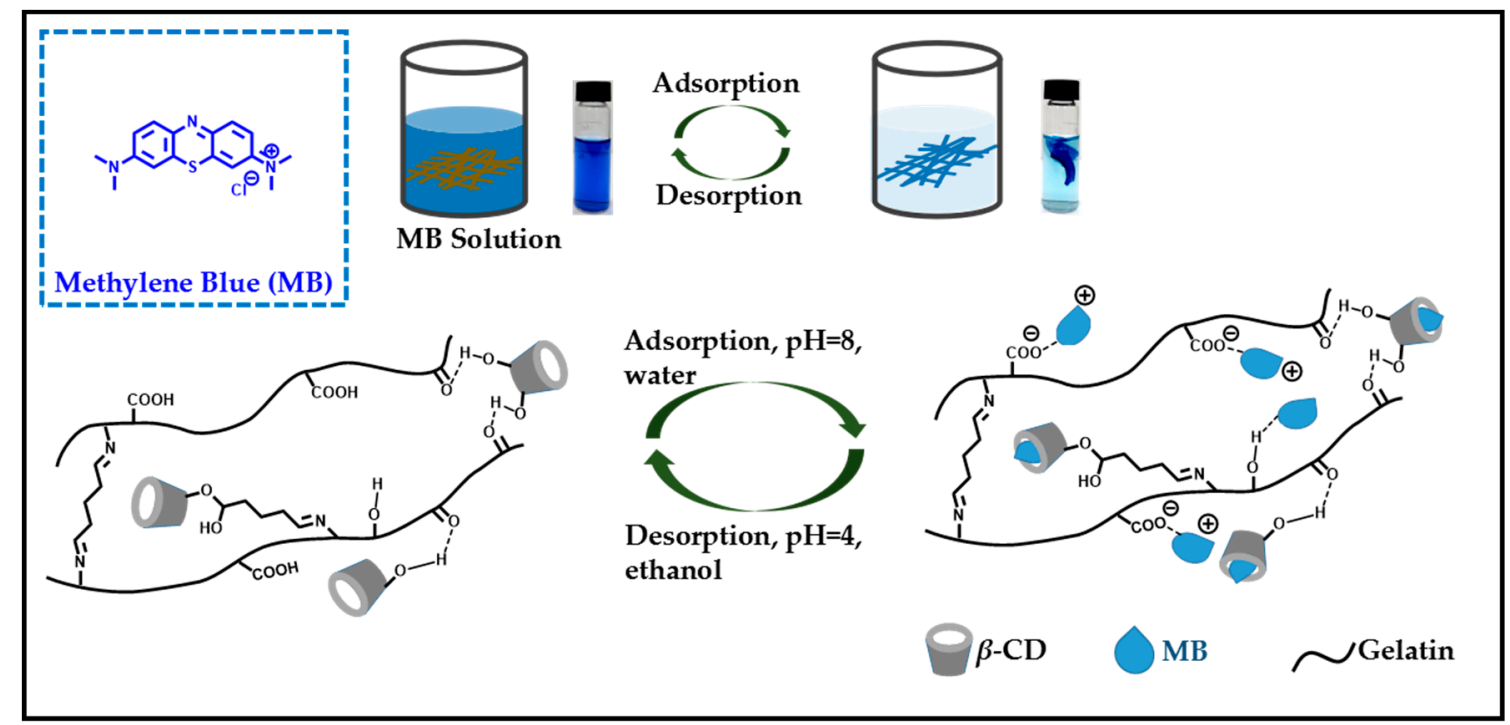

Scheme 2. The adsorption and desorption mechanism of $\mathrm{MB}$ onto gelatin/ $\beta$-CD composite fiber adsorbents.

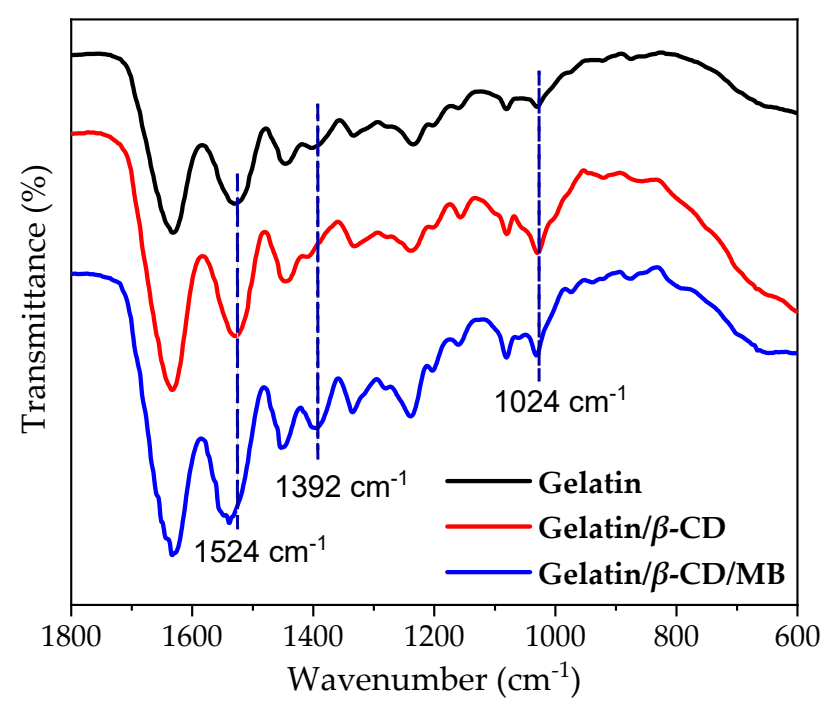

Figure 11. FTIR spectrum of gelatin fibers, gelatin $/ \beta-\mathrm{CD}$ composite fiber adsorbents and gelatin $/ \beta-\mathrm{CD}$ composite fiber adsorbents with MB adsorption. 


\section{Materials and Methods}

\subsection{Materials}

Gelatin (type B, basic-processed, obtained from bones, with a molecular weight of 100,000, viscosity value of $4.9 \mathrm{MPa} \cdot \mathrm{s}^{-1}$ ) was provided by Dongbao Bio-Tech Co., Ltd. (Baotou, China). $\beta$-cyclodextrin ( $\beta$-CD), 2,2,2-trifluoroethanol, glutaraldehyde (25 wt \%), methylene blue trihydrate IND, basic fuchsin, gentian violet, brilliant blue $\mathrm{R}$, malachite green and ethanol absolute were purchased from Titan Scientific Co., Ltd. (Shanghai, China). The deionized water used in the experiments possessed a resistivity of $18.2 \mathrm{M} \Omega \cdot \mathrm{cm}$. All chemical reagents were analytical grade and employed without post-processing.

\subsection{Preparation of Gelatin/ $\beta-C D$ Composite Fiber Adsorbents}

For the preparation of gelatin / $\beta$-CD composite fiber adsorbents, gelatin $(15 \%, w / w)$ was dissolved in 2,2,2-trifluoroethanol with constant stirring at $45^{\circ} \mathrm{C}$ for $1 \mathrm{~h}$, then $\beta$ - $\mathrm{CD}(0 \%, 15 \%, 30 \%, 50 \%$ and $65 \%$ on the weight of gelatin, respectively) was added to the solution, and the homogeneous liquid was obtained by ultrasonic. For the electrospinning process, the solution was poured into the injection and connected to a high voltage power supply. The needle tip to the collector drum distance was fixed at $15 \mathrm{~cm}$. The fibers were spun with a flow rate of $6 \mathrm{~mL} \cdot \mathrm{h}^{-1}$ at $17 \mathrm{kV}$. After electrospinning, the obtained fibers were soaked in glutaraldehyde ethanol solution $(0.25 \%, v / v)$ for $12 \mathrm{~h}$ and then freeze-dried for 5 $\mathrm{h}$ for further use.

\subsection{Morphologies of the Fiber Surface}

The morphologies of fiber surface were observed by a field emission scanning electron microscope (FESEM, Vltra55, Carl Zeiss SMT Pte Ltd., Oberkochen, Germany) under an accelerating voltage of $3 \mathrm{kV}$. Samples were sprayed with gold coating. Images were registered at 20,000 and 60,000× magnifications.

\subsection{FTIR Analysis}

A spectrometer (Bruker Tensor II, Karlsruhe, Germany) with the digital attenuated total reflectance (ATR) accessory was used to obtain the FTIR absorbance spectra in the range of $4000-400 \mathrm{~cm}^{-1}$. Each spectrum was obtained at a resolution of $0.3 \mathrm{~cm}^{-1}$ with an average of 32 consecutive scans.

\subsection{Mechanical Properties}

Adsorbent thickness was the average value of four different measurement results on each specimen taken with a micrometer. Then, the texture analyzer (Instron, Norwood, CO, USA) was used to measure the tensile strength and percent elongation of adsorbents. The analysis was performed on $10 \mathrm{~mm} \times 20 \mathrm{~mm}$ strips. The initial grip separation and crosshead speed were set at $12 \mathrm{~mm}$ and $50 \mathrm{~mm} \cdot \mathrm{min}^{-1}$, respectively. The percentage elongation $(\mathrm{E} \%)$ and tensile strength of the adsorbents were calculated by the following equations:

$$
\begin{gathered}
\mathrm{E} \%=\frac{1-1_{0}}{1} \times 100 \% \\
\text { Tensile strength }=\frac{\text { maximum force }(\mathrm{N})}{\text { thickness }(\mathrm{mm}) \times \text { width }(\mathrm{mm})} \times 100 \%
\end{gathered}
$$

where $l_{0}$ and 1 represent the initial length and the length at the break point of the adsorbent, respectively. The result was an average of three measurements.

\subsection{Adsorption of $M B$}

Briefly, $10 \mathrm{mg}$ composite fiber adsorbent was added into $8.0 \mathrm{~mL} \mathrm{MB}$ solution $\left(20.0 \mathrm{mg} \cdot \mathrm{L}^{-1}\right.$, $\mathrm{pH}=8.0$ ). The mixture was shaken at a constant speed of $120 \mathrm{rpm}$. After different time intervals, the 
adsorption mixture was centrifuged from its suspension; the concentration of MB was detected by a UV-vis spectrophotometer at the maximum adsorption wavelength of $664 \mathrm{~nm}$. The dye concentration in the solution was calculated according to the standard curve equation, and the adsorption capacity $q_{t}$ (Equation (8)) and adsorption efficiency $\rho$ (Equation (9)) were calculated by the change of methylene blue concentration before and after adsorption [57].

$$
\begin{gathered}
q_{t}=\frac{\left(c_{0}-c_{t}\right) \times \mathrm{V}}{\mathrm{M}} \\
\rho=\frac{c_{0}-c_{t}}{c_{0}} \times 100 \%,
\end{gathered}
$$

where $c_{0}\left(\mathrm{mg} \cdot \mathrm{L}^{-1}\right)$ is the initial concentration of $\mathrm{MB}, c_{t}\left(\mathrm{mg} \cdot \mathrm{L}^{-1}\right)$ is the $\mathrm{MB}$ concentration at time $t, \mathrm{~V}$ is the volume of the testing solution $(\mathrm{L})$ and $\mathrm{M}$ is the weight of the adsorbent $(\mathrm{g})$.

\subsection{Desorption and Recycling Study}

In the desorption experiment, the composite fiber adsorbents adsorbed on MB were thoroughly cleaned with deionized water, and the adsorbents were then placed in ethanol solutions containing $\mathrm{HCl}(5 \% v / v)$. After desorption equilibrium, the adsorbents were washed several times with deionized water and freeze-dried. Finally, the adsorbents were reused in adsorption experiments (adsorbent, $10.0 \mathrm{mg}$; MB, $8.0 \mathrm{~mL}, 20.0 \mathrm{mg} \cdot \mathrm{L}^{-1}$ ). The above processes were repeated 10 times to investigate the regeneration ability of the adsorbents.

\section{Conclusions}

A kind of environmentally friendly gelatin $/ \beta$-CD composite fiber adsorbent was prepared by blending natural macromolecule gelatin with $\beta-\mathrm{CD}$ via the electrospinning technique. The composite fiber adsorbents exhibit excellent mechanical strength and high removal efficiency for MB. The adsorption isotherm and kinetics studies suggest that the equilibrium adsorption data and adsorption kinetics are well described by the Langmuir isotherm model and the pseudo-second-order kinetic model, respectively. The theoretical maximum adsorption capacity is $47.4 \mathrm{mg} \cdot \mathrm{g}^{-1}$. It is worth noting that after nine cycles of desorption-adsorption regeneration, the composite fiber adsorbents still maintain high adsorption efficiency. Additionally, gelatin/ $\beta$-CD composite fiber adsorbents possess excellent adsorption properties for basic fuchsin, gentian violet, brilliant blue $\mathrm{R}$ and malachite green dyes. The experimental results imply that the gelatin/ $\beta$-CD composite fiber adsorbents have excellent adsorption application prospects for the removal of dyes from wastewater.

Author Contributions: W.L., Y.G. and Y.C. conceived and designed the experiments; Y.C., Y.M., Y.Z., W.L. and Y.S. performed the experiments and analyzed the data; H.L. contributed reagents/materials/analysis tools; Y.C., Y.M. and W.L. wrote the paper.

Funding: This work was supported by the State Natural Sciences Fund, China (Project No. 21506236, 51372276), Research and Application of Gelatin Green Manufacturing 2.0 Technology by Enzymatic method (KFJ-STS-ZDTP-016) and Hangzhou Research Institute of Technical Institute of Physics and Chemistry, CAS Fund (Project No. 2016050201, 2016050202).

Conflicts of Interest: The authors declare no conflict of interest.

\section{References}

1. Bohdziewicz, J.; Sroka, E. Treatment of wastewater from the meat industry applying integrated membrane systems. Process Biochem. 2005, 40, 1339-1346. [CrossRef]

2. Sleiman, M.; Vildozo, D.; Ferronato, C.; Chovelon, J.M. Photocatalytic degradation of azo dye Metanil Yellow: Optimization and kinetic modeling using a chemometric approach. Appl. Catal. B Environ. 2007, 77, 1-11. [CrossRef]

3. Fan, L.; Zhou, Y.; Yang, W.; Chen, G.; Yang, F. Electrochemical degradation of aqueous solution of Amaranth azo dye on ACF under potentiostatic model. Dyes Pigments 2008, 76, 440-446. [CrossRef] 
4. Zhu, M.X.; Lee, L.; Wang, H.H.; Wang, Z. Removal of an anionic dye by adsorption/precipitation processes using alkaline white mud. J. Hazard. Mater. 2007, 149, 735-741. [CrossRef] [PubMed]

5. Crini, G. Recent developments in polysaccharide-based materials used as adsorbents in wastewater treatment. Prog. Polym. Sci. 2005, 30, 38-70. [CrossRef]

6. Butler, E.; Hung, Y.T.; Yeh, Y.L.; Ahmad, M.S.A. Electrocoagulation in wastewater treatment. Water 2011, 3, 495-525. [CrossRef]

7. Ren, Y.; Cui, C.; Wang, P. Pomelo peel modified with citrate as a sustainable adsorbent for removal of methylene blue from aqueous solution. Molecules 2018, 23, 1342. [CrossRef] [PubMed]

8. Dizbay-Onat, M.; Vaidya, U.K.; Balanay, J.A.G.; Lungu, C.T. Preparation and characterization of flax, hemp and sisal fiber-derived mesoporous activated carbon adsorbents. Adsorpt. Sci. Technol. 2018, 36, 441-457. [CrossRef]

9. Kausar, A.; Iqbal, M.; Javed, A.; Aftab, K.; Nazli, Z.H.; Bhatti, H.N.; Nouren, S. Dyes adsorption using clay and modified clay: A review. J. Mol. Liq. 2018, 256, 395-407. [CrossRef]

10. Sánchez-Zambrano, K.S.; Duarte, L.L.; Soares Maia, D.A.; Vilarrasa-Garcia, E.; Bastos-Neto, M.; Rodriguez-Castellon, E.; Silva de Azevedo, D.C. $\mathrm{CO}_{2}$ capture with mesoporous silicas modified with amines by double functionalization: Assessment of adsorption/desorption cycles. Materials 2018, 11, 887. [CrossRef] [PubMed]

11. Lv, X.; Zhao, M.; Chen, Z.; Zhang, J.; Tian, X.; Ren, X.; Mei, X. Prepare porous silica nanospheres for water sustainability: High efficient and recyclable adsorbent for cationic organic dyes. Colloid Polym. Sci. 2018, 296, 59-70. [CrossRef]

12. MiarAlipour, S.; Friedmann, D.; Scott, J.; Amal, R. $\mathrm{TiO}_{2}$ /porous adsorbents: Recent advances and novel applications. J. Hazard. Mater. 2018, 341, 404-423. [CrossRef] [PubMed]

13. Salama, A.; Mohamed, A.; Aboamera, N.M.; Osman, T.; Khattab, A. Characterization and mechanical properties of cellulose acetate/carbon nanotube composite nanofibers. Adv. Polym. Technol. 2017, 36, 1-6. [CrossRef]

14. Li, M.; Wang, H.; Wu, S.; Li, F.; Zhi, P. Adsorption of hazardous dyes indigo carmine and acid red on nanofiber membranes. RSC Adv. 2012, 2, 900-907. [CrossRef]

15. Supaphol, P.; Suwantong, O.; Sangsanoh, P.; Srinivasan, S.; Jayakumar, R.; Nair, S.V. Electrospinning of biocompatible polymers and their potentials in biomedical applications. Adv. Polym. Sci. 2012, 246, 213-239.

16. Mahmoodi, N.M.; Mokhtari-Shourijeh, Z.; Abdi, J. Preparation of mesoporous polyvinyl alcohol/ chitosan/silica composite nanofiber and dye removal from wastewater. Environ. Prog. Sustain. 2018. [CrossRef]

17. Huang, F.; Xu, Y.; Liao, S.; Yang, D.; Hsieh, Y.L.; Wei, Q. Preparation of Amidoxime Polyacrylonitrile Chelating Nanofibers and Their Application for Adsorption of Metal Ions. Materials 2013, 6, 969-980. [CrossRef] [PubMed]

18. Tian, Y.; Wu, M.; Liu, R.; Li, Y.; Wang, D.; Tan, J.; Wu, R.; Huang, Y. Electrospun membrane of cellulose acetate for heavy metal ion adsorption in water treatment. Carbohyd. Polym. 2011, 83, 743-748. [CrossRef]

19. Choi, J.; Ide, A.; Truong, Y.B.; Kyratzis, I.L.; Caruso, R.A. High surface area mesoporous titanium-zirconium oxide nanofibrous web: A heavy metal ion adsorbent. J. Mater. Chem. A 2013, 1, 5847-5853. [CrossRef]

20. Wu, S.; Li, F.; Wang, H.; Fu, L.; Zhang, B.; Li, G. Effects of poly (vinyl alcohol) (PVA) content on preparation of novel thiol-functionalized mesoporous $\mathrm{PVA} / \mathrm{SiO}_{2}$ composite nanofiber membranes and their application for adsorption of heavy metal ions from aqueous solution. Polymer 2010, 51, 6203-6211. [CrossRef]

21. Chen, X.; Parker, S.G.; Zou, G.; Su, W.; Zhang, Q. Beta-cyclodextrin-functionalized silver nanoparticles for the naked eye detection of aromatic isomers. ACS Nano 2010, 4, 6387-6394. [CrossRef] [PubMed]

22. Ozmen, E.Y.; Sezgin, M.; Yilmaz, A.; Yilmaz, M. Synthesis of beta-cyclodextrin and starch based polymers for sorption of azo dyes from aqueous solutions. Bioresour. Technol. 2008, 99, 526-531. [CrossRef] [PubMed]

23. Huang, J.; Wang, L.; Shi, C.; Dai, Y.; Gu, C.; Liu, J. Selective detection of picric acid using functionalized reduced graphene oxide sensor device. Sens. Actuators B Chem. 2014, 196, 567-573. [CrossRef]

24. Chen, H.; Ji, H.; Zhou, X.; Wang, L. Green synthesis of natural benzaldehyde from cinnamon oil catalyzed by hydroxypropyl- $\beta$-cyclodextrin. Tetrahedron 2010, 66, 9888-9893. [CrossRef]

25. Kadam, V.; Truong, Y.B.; Easton, C.; Mukherjee, S.; Wang, L.; Padhye, R.; Kyratzis, I.L. Electrospun Polyacrylonitrile/ $\beta$-Cyclodextrin composite membranes for simultaneous air filtration and adsorption of volatile organic compounds. ACS Appl. Nano Mater. 2018. [CrossRef] 
26. Schäfer, A.I.; Stelzl, K.; Faghih, M.; Sen Gupta, S.; Krishnadas, K.R.; Heißler, S.; Pradeep, T. Poly(ether sulfone) nanofibers impregnated with $\beta$-Cyclodextrin for increased micropollutant removal from water. ACS Sustain. Chem. Eng. 2017, 6, 2942-2953. [CrossRef]

27. Zhao, R.; Wang, Y.; Li, X.; Sun, B.; Jiang, Z.; Wang, C. Water-insoluble sericin/beta-cyclodextrin/PVA composite electrospun nanofibers as effective adsorbents for methylene blue. Colloids Surf. B 2015, 136, 375-382. [CrossRef] [PubMed]

28. Xin, Q.; Fu, J.; Chen, Z.; Liu, S.; Yan, Y.; Zhang, J.; Xu, Q. Polypyrrole nanofibers as a high-efficient adsorbent for the removal of methyl orange from aqueous solution. J. Environ. Chem. Eng. 2015, 3, 1637-1647. [CrossRef]

29. Yousefi Abdolmaleki, A.; Zilouei, H.; Nouri Khorasani, S.; Abdolmaleki, A. Optimization and characterization of electrospun chitosan/poly(vinyl alcohol) nanofibers as a phenol adsorbent via response surface methodology. Polym. Adv. Technol. 2017, 28, 1872-1878. [CrossRef]

30. Shu, W.X.; Zheng, J.P.; Lei, T.; Kang, D.Y. Interaction of functional groups of gelatin and montmorillonite in nanocomposite. J. Appl. Polym. Sci. 2006, 101, 1556-1561.

31. MaHam, A.; Tang, Z.; Wu, H.; Wang, J.; Lin, Y. Protein-based nanomedicine platforms for drug delivery. Small 2009, 5, 1706-1721. [CrossRef] [PubMed]

32. Ghosh, S.K.; Adhikary, P.; Jana, S.; Biswas, A.; Sencadas, V.; Gupta, S.D.; Tudu, B.; Mandal, D. Electrospun gelatin nanofiber based self-powered bio-e-skin for health care monitoring. Nano Energy 2017, 36, $166-175$. [CrossRef]

33. Correia, D.M.; Padrão, J.; Rodrigues, L.R.; Dourado, F.; Lanceros-Méndez, S.; Sencadas, V. Thermal and hydrolytic degradation of electrospun fish gelatin membranes. Polym. Test. 2018, 32, 995-1000. [CrossRef]

34. Kishan, A.P.; Nezarati, R.M.; Radzicki, C.M.; Renfro, A.L.; Robinson, J.L.; Whitely, M.E.; Cosgriff-Hernandez, E.M. In situ crosslinking of electrospun gelatin for improved fiber morphology retention and tunable degradation. J. Mater. Chem. B 2015, 3, 7930-7938. [CrossRef]

35. Morsy, R.; Hosny, M.; Reicha, F.; Elnimr, T. Developing and physicochemical evaluation of cross-linked electrospun gelatineglycerol nanofibrous membranes for medical applications. J. Mol. Struct. 2017, 1135, 222-227. [CrossRef]

36. Shi, C.; Zhuang, C.; Cui, Y.; Tao, F. Preparation and characterization of gelatin film modified by cellulose active ester. Polym. Bull. 2017, 74, 3505-3525. [CrossRef]

37. Lin, L.; Regenstein, J.M.; Lv, S.; Lu, J.; Jiang, S. An overview of gelatin derived from aquatic animals: Properties and modification. Trends Food Sci. Technol. 2017, 68, 102-112. [CrossRef]

38. Honda, Y.; Takeda, Y.; Li, P.; Huang, A.; Sasayama, S.; Hara, E.; Uemura, N.; Ueda, M.; Hashimoto, M.; Arita, K.; et al. Epigallocatechin Gallate-modified gelatin sponges treated by vacuum heating as a novel scaffold for bone tissue engineering. Molecules 2018, 23, 876. [CrossRef] [PubMed]

39. Jalaja, K.; Naskar, D.; Kundu, S.C.; James, N.R. Fabrication of cationized gelatin nanofibers by electrospinning for tissue regeneration. RSC Adv. 2015, 5, 89521-89530.

40. Chen, Y.; Lu, W.; Guo, Y.; Zhu, Y.; Lu, H.; Wu, Y. Superhydrophobic coatings on gelatin-based films: Fabrication, characterization and cytotoxicity studies. RSC Adv. 2018, 8, 23712-23719. [CrossRef]

41. Gupta, N.; Santhiya, D. In situ mineralization of bioactive glass in gelatin matrix. Mater. Lett. 2017, 188, 127-129. [CrossRef]

42. Singh, K.; Ingole, P.G.; Bajaj, H.C.; Gupta, H. Preparation, characterization and application of $\beta$-cyclodextrin-glutaraldehyde crosslinked membrane for the enantiomeric separation of amino acids. Desalination 2012, 298, 13-21. [CrossRef]

43. Lee, J.Y.; Hsu, C.H.; Su, C.I.; Murakami, R.I.; Lin, C.W.; Lu, C.H. A Study on Activated Carbon Nanofibrous Adsorbents Prepared by Technology for Electrospun Composite Yarn. Fiber Polym. 2015, 16, 2437-2444. [CrossRef]

44. Abou-Zeid, R.E.; Dakrory, S.; Ali, K.A.; Kamel, S. Novel method of preparation of tricarboxylic cellulose nanofiber for efficient removal of heavy metal ions from aqueous solution. Int. J. Biol. Macromol. 2018, 119, 207-214. [CrossRef] [PubMed]

45. Habiba, U.; Siddique, T.A.; Lee, J.J.L.; Tan, C.J.; Ang, B.C.; Afifi, A.M. Adsorption study of Methyl orange by Chitosan/Polyvinyl Alcohol/Zeolite Electrospun Composite Nanofibrous Membrane. Carbohyd. Polym. 2018, 191, 79-85. [CrossRef] [PubMed] 
46. Li, Y.; Sun, J.; Du, Q.; Zhang, L.; Yang, X.; Wu, S.; Xia, Y.; Wang, Z.; Xia, L.; Cao, A. Mechanical and dye adsorption properties of graphene oxide/chitosan composite fibers prepared by wet spinning. Carbohydr. Polym. 2014, 102, 755-761. [CrossRef] [PubMed]

47. Lee, T.; Lim, J.; Chung, I.; Kim, I.; HaPang, C.-S. Preparation and Characterization of Polyimide/Modified $\beta$-Cyclodextrin Nanocomposite Films. Macromol. Res. 2010, 18, 120-128. [CrossRef]

48. Pang, J.; Fu, F.; Ding, Z.; Lu, J.; Li, N.; Tang, B. Adsorption behaviors of methylene blue from aqueous solution on mesoporous birnessite. J. Taiwan Inst. Chem. Eng. 2017, 77, 168-176. [CrossRef]

49. Crini, G. Kinetic and equilibrium studies on the removal of cationic dyes from aqueous solution by adsorption onto a cyclodextrin polymer. Dyes Pigments 2008, 77, 415-426. [CrossRef]

50. Liu, Q.; Zhong, L.B.; Zhao, Q.B.; Frear, C.; Zheng, Y.M. Synthesis of $\mathrm{Fe}_{3} \mathrm{O}_{4}$ /Polyacrylonitrile composite electrospun nanofiber mat for effective adsorption of Tetracycline. ACS Appl. Mater. Interfaces 2015, 7, 14573-14583. [CrossRef] [PubMed]

51. Zhao, R.; Wang, Y.; Li, X.; Sun, B.; Wang, C. Synthesis of beta-Cyclodextrin-based electrospun nanofiber membranes for highly efficient adsorption and separation of methylene Blue. ACS Appl. Mater. Interfaces 2015, 7, 26649-26657. [CrossRef] [PubMed]

52. Crini, G.; Peindy, H.; Gimbert, F.; Robert, C. Removal of CI Basic Green 4 (Malachite Green) from aqueous solutions by adsorption using cyclodextrin-based adsorbent: Kinetic and equilibrium studies. Sep. Purif. Technol. 2007, 53, 97-110. [CrossRef]

53. Mckay, G. Adsorption of dyestuffs from aqueous solutions with activated carbon II: Column studies and simplified design models. J. Chem. Technol. Biotechnol. 1982, 32, 773-780. [CrossRef]

54. Weber, T.W.; Chakravorti, R.K. Pore and solid diffusion models for fixed-bed adsorbers. AICHE J. 1974, 20, 228-238. [CrossRef]

55. Lezanska, M.; Olejniczak, A.; Rokicinsk, A.; Kustrowsk, P.; Lukaszewic, J. Type A and B gelatin as precursors of silicatemplated porous carbon with a specified number of nitrogen- and oxygen-containing functionalities. Mater. Express 2017, 7, 123-133. [CrossRef]

56. Voron'ko, N.; Derkach, S.; Kuchina, Y.; Sokolan, N. The chitosan-gelatin (bio)polyelectrolyte complexes formation in an acidic medium. Carbohydr. Polym. 2016, 138, 265-272. [CrossRef] [PubMed]

57. Rakass, S.; Mohmoud, A.; Oudghiri Hassani, H.; Abboudi, M.; Kooli, F.; Al Wadaani, F. Modified nigella sativa seeds as a novel efficient natural adsorbent for removal of methylene blue dye. Molecules 2018, 23, 1950. [CrossRef] [PubMed]

Sample Availability: Samples of the compounds S0-S4 are available from the authors.

(C) 2018 by the authors. Licensee MDPI, Basel, Switzerland. This article is an open access article distributed under the terms and conditions of the Creative Commons Attribution (CC BY) license (http:// creativecommons.org/licenses/by/4.0/). 